\title{
Increased platelet reactivity in dyslipidemic patients with coronary artery disease on dual anti-platelet therapy
}

Bernhard Jäger ${ }^{1}$, Editha Piackova ${ }^{1}$, Paul Michael Haller ${ }^{1}$, Tijana Andric $^{1}$, Beatrice Kahl ${ }^{1}$, Günther Christ², Alexander Geppert ${ }^{1}$, Johann Wojta ${ }^{3,4}$, Kurt Huber ${ }^{1,5}$

\author{
${ }^{1} 3^{\text {rd }}$ Medical Department, Cardiology and Intensive Care Medicine, \\ Wilhelminenhospital, Vienna, Austria \\ $25^{\text {th }}$ Medical Department with Cardiology, Kaiser Franz Josef Hospital, Vienna, Austria \\ ${ }^{3}$ Department of Cardiology, Medical University Vienna, Vienna, Austria \\ ${ }^{4}$ Cardiovascular Research, Ludwig Boltzmann Cluster, Vienna, Austria \\ ${ }^{5}$ Medical Faculty, Sigmund Freud University, Vienna, Austria
}

Submitted: 22 June 2017

Accepted: 9 September 2017

Arch Med Sci 2019; 15, 1: 65-71

DOI: https://doi.org/10.5114/aoms.2018.81035

Copyright $\odot 2018$ Termedia \& Banach

\section{Abstract}

Introduction: The optimal duration of dual anti-platelet therapy (DAPT) following percutaneous coronary intervention $(\mathrm{PCI})$ is still a matter of debate. Biomarkers may help to identify patients who will benefit from extended DAPT. The aim of the study was to test the interaction between lipid parameters and platelet function in patients with coronary artery disease (CAD) on DAPT.

Material and methods: Overall, 58 patients on DAPT were prospectively included following PCI in stable CAD. Platelet markers, i.e. mean platelet volume (MPV), platelet distribution width (PDW), fraction of reticulated thrombocytes (RT) and ADP-induced multiple electrode aggregometry (MEA), as well as serum lipids, i.e. high-density lipoprotein cholesterol (HDL-C), low-density lipoprotein cholesterol (LDL-C), total cholesterol (TC), triglycerides (TG) and remnant cholesterol (RC), were assessed after intake of a maintenance dose of ASA and P2Y12 inhibitor.

Results: A significant inverse correlation was found for HDL-C levels and markers of platelet activation: MPV $(r=-0.351, p=0.009)$, PDW $(r=-0.391, p=$ $0.003)$, fraction of RT $(r=-0.402, p=0.003)$ and ADP-induced MEA $(r=-0.345$, $p=0.011$ ). Only a weak or no association was found between other lipid parameters and platelet markers. After multivariable adjustment, HDL-C levels served as a strong and significant predictor of MPV $(95 \% \mathrm{Cl}:-0.039$ to -0.009 ; $p=0.002)$, PDW (95\% Cl: -0.094 to $-0.034 ; p<0.0001)$, RT $(95 \% \mathrm{Cl}:-0.107$ to $-0.031 ; p=0.001)$ and MEA (95\% Cl: -0.540 to $-0.170 ; p<0.0001)$, while TG, LDL-C, RC and TC were not significantly associated with platelet function. Conclusions: Within lipid parameters, only HDL-C levels are strongly associated with markers of platelet activation in CAD patients on DAPT. Accordingly, detection of dyslipidemia might indicate the need for prolongation of DAPT.

Key words: P2Y12 inhibitor, platelet function, platelet activation, highdensity lipoprotein cholesterol, dyslipidemia.

\section{Introduction}

Current guidelines recommend dual anti-platelet therapy (DAPT) for 6 (in stable coronary artery disease (CAD) after implantation of drug-eluting stents (DES)) to 12 months (in acute coronary syndrome (ACS) inde-

\author{
Corresponding author: \\ Bernhard Jäger \\ $3^{\text {rd }}$ Medical Department, \\ Cardiology and Intensive \\ Care Medicine \\ Wilhelminenhospital \\ Montleartstrasse 37 \\ 1140 Vienna, Austria \\ Phone: +43 6767336698 \\ E-mail: bernhard.jaeger@ \\ meduniwien.ac.at
}


pendent of treatment strategy) in patients with CAD following percutaneous coronary intervention (PCI) [1-3]. However, the optimal duration of DAPT is an ongoing matter of debate [4] and distinct patients with high ischemic and low bleeding risk might benefit from extended DAPT [5]. Recently, a clinical risk score was introduced to assess the optimal duration of DAPT after PCI [6]. Additionally, several biomarkers are currently investigated in order to identify patients who will benefit from prolonged or intensified DAPT.

Atherogenic dyslipidemia, like that seen in diabetes, is characterized as a condition with elevated plasma triglycerides (TG), reduced plasma concentration of high-density lipoprotein cholesterol (HDL-C) and a shift towards small dense low-density lipoprotein (LDL) [7]. Epidemiological and clinical studies have shown reduced cardiovascular mortality in patients with high levels of HDL-C, which was considered to exert beneficial effects for many years $[8,9]$. This was mainly attributed to its ability of reverse cholesterol transport and to the anti-oxidative, anti-inflammatory and vasodilatory properties of HDL-C [10]. However, in a recent Mendelian randomization study conducted in 73,513 participants from three Danish studies genetic variants that only affected HDL-C plasma levels - as opposed to remnant cholesterol (RC) - were not related to the development of ischemic events, challenging the causal relationship between HDL-C levels and cardiovascular disease [11]. These new data suggest that triglyceride-rich lipoproteins play an active role in the development of CAD, making HDL-C possibly only an innocent bystander of other risk factors [12, 13].

Previous studies, mainly performed in animal models or ex vivo, have investigated the association of platelet function and HDL-C [14]. High levels of HDL-C were independently associated with decreased ex vivo thrombus formation in patients without coronary artery disease [15]. Moreover, the administration of reconstituted HDL particles reduced ex vivo platelet reactivity in healthy individuals and in diabetic patients [16, 17]. Despite these experimental data, the association of platelet function and HDL-C has never been tested in the clinical setting of modern anti-platelet therapy following PCI with modern drug-eluting stents. Therefore, the aim of the present study was to investigate the relationship of routine lipid parameters and markers of platelet activation in patients with CAD on contemporary DAPT.

\section{Material and methods}

\section{Patients}

Patients with CAD on a DAPT maintenance dose including ASA (100 mg) plus clopidogrel (75 mg OD), or prasugrel (10 mg OD), or ticagrelor (90 mg BID) were prospectively enrolled during a stable phase after coronary artery stent implantation in a single-center study conducted in the out-patient ward of a tertiary center of cardiology. All patients were free from ischemic or bleeding events for at least 6 months and had sinus rhythm. Patients on oral anticoagulation or on other antiplatelet drugs than those mentioned above were deemed ineligible. Each subject gave his/her written informed consent before any study procedure. The study was approved by the local ethics committee and was conducted according to the Declaration of Helsinki.

\section{Blood sampling}

Blood samples were drawn from an antecubital vein during a routine outpatient visit $2-4 \mathrm{~h}$ after intake of morning medication and were rapidly processed to avoid swelling of platelets in EDTA blood [18]. Mean platelet volume (MPV, fl), platelet distribution width (PDW, $\mathrm{fl}$ ), and the fraction of reticulated thrombocytes (RT) were analyzed by an automated Hematology Analyzer (Sysmex XN-3000, Kobe, Japan). ADP-induced multiple electrode aggregometry (MEA) was determined by the Multiplate analyzer (Roche diagnostics, Basel, Switzerland), as previously described [19]. Briefly, the agonist ADP was added to anticoagulated whole blood (hirudin) to a final concentration of $6.4 \mu \mathrm{mol} / /$ ADP plus $9.4 \mathrm{nmol} / /$ PGE $_{1}$ (ADPtest high sensitivity). Platelet aggregation was continuously recorded for $6 \mathrm{~min}$ and quantified as area under the aggregation curve $(A U C=A U \times$ min) of aggregation units (AU). Remnant cholesterol (RC) was calculated from non-fasting samples via the equation ( $\mathrm{RC}=\mathrm{TC}-\mathrm{HDL}-\mathrm{C}-\mathrm{LDL}-\mathrm{C})$ as previously described [20].

\section{Statistical analysis}

Baseline characteristics are expressed as frequencies and percentages. The Pearson correlation coefficient was used to explore the strength of association between markers of platelet activation (MPV, PDW, RT, MEA) and routine lipid parameters (HDL-C, LDL-C, TC, TG, RC). Multivariable analysis with step-wise backward elimination of variables using a likelihood ratio test with a $p$-value of 0.05 for entry and a $p$-value of 0.15 for removal was performed to identify independent predictors for each of the four pre-specified markers of platelet reactivity (MPV, PDW, RT, MEA). The following known and identified markers of platelet activation were entered into the model: $\mathrm{HDL}-\mathrm{C}$, TC, TG, sex, age, platelet count, high-dose statin intake (as previously defined [21]), current smoking, index event (acute coronary syndrome vs. sta- 
ble CAD), P2Y12 inhibitor (clopidogrel, prasugrel, or ticagrelor), PPI intake, diabetes mellitus, body mass index, and glomerular filtration rate (calculated via the MDRD formula).

\section{Results}

A total of 58 patients on DAPT (clopidogrel: $n=18$, prasugrel: $n=17$, ticagrelor: $n=23$ ) were enrolled between July 2014 and November 2015. Baseline characteristics are shown in Table I. About $28 \%$ of patients had undergone coronary stent implantation for stable CAD, whereas the majority of the study population was included after an index event of acute coronary syndrome. Concomitant treatment included $\beta$-blockers, ACE inhibitors or angiotensin receptor blockers and statin therapy in more than $70 \%$ of patients each.

A significant inverse correlation was found for HDL-C levels and markers of platelet activation in univariable analysis, as shown in Figure 1: MPV $(r=-0.351, p=0.009)$, PDW $(r=-0.391, p=0.003)$, fraction of reticulated thrombocytes $(r=-0.402$, $p=0.003)$ and ADP-induced MEA $(r=-0.345$, $p=0.011)$. Triglycerides $(r=0.231, p=0.092)$ and glycated hemoglobin $\left(\mathrm{HbA}_{1 \mathrm{c}}\right)$ levels $(r=0.314$, $p=0.024)$ correlated with reticulated thrombocytes, but not with other markers of platelet function. No association was found between TC, LDL-C, $\mathrm{RC}$ and markers of platelet activation (Table II).

The MPV $(r=0.231, p=0.08)$ and PDW $(r=$ $0.255, p=0.054)$ exhibited a moderate correlation with body mass index, while a history of diabetes mellitus was associated with higher levels of MPV (10.8 vs. 10.28fl, $p=0.017$ ), PDW (13.18vs. $11.90 \mathrm{fl}$, $p=0.006)$, reticulated thrombocytes (4.8\% vs. $3.3 \%, p=0.008)$, and on-treatment ADP-induced platelet reactivity (MEA: 21.0 vs. $18.3 \mathrm{AU}, p=$ 0.273). Markers of platelet activation were not different with respect to a clinical diagnosis of hyperlipidemia.

After adjusting for known and identified confounders of platelet activation and other lipid parameters in a linear regression model using backward elimination, HDL-C levels served as strong and significant predictors of MPV (95\% Cl: -0.039 to $-0.009 ; p=0.002)$, PDW (95\% Cl: -0.094 to $-0.034 ; p<0.0001)$, reticulated thrombocytes (95\% Cl: -0.107 to $-0.031 ; p=0.001$ ) and MEA (95\% Cl: -0.540 to $-0.170 ; p<0.0001$ ), while TG, LDL-C, RC and TC were not significantly associated with platelet function (Table III).

\section{Discussion}

The present study offers new insights into the interaction of platelet activity and routine markers of dyslipidemia, diabetes and metabolic syndrome in patients with CAD on chronic medication with
Table I. Baseline characteristics

\begin{tabular}{|c|c|c|}
\hline \multicolumn{2}{|l|}{ Parameter } & Value \\
\hline \multicolumn{2}{|c|}{ Age, mean \pm SD [years] } & $62.7 \pm 11.2$ \\
\hline \multicolumn{2}{|c|}{ Body mass index, mean $\pm \mathrm{SD}\left[\mathrm{kg} / \mathrm{m}^{2}\right]$} & $28.7 \pm 4.6$ \\
\hline \multicolumn{2}{|l|}{ Male sex, \% $(n)$} & $74.1 \%(43)$ \\
\hline \multirow{3}{*}{$\begin{array}{l}\text { P2Y12 inhibitor, } \\
\%(n)\end{array}$} & Clopidogrel & $31.0 \%(18)$ \\
\hline & Prasugrel & $29.3 \%(17)$ \\
\hline & Ticagrelor & $39.7 \%(23)$ \\
\hline \multirow{4}{*}{$\begin{array}{l}\text { Indication } \\
\text { for PCI/index } \\
\text { event, \% (n) }\end{array}$} & Stable CAD & $27.6 \%(16)$ \\
\hline & STEMI & $37.9 \%(22)$ \\
\hline & NSTEMI & $31.0 \%(18)$ \\
\hline & Unstable angina & $3.4 \%(2)$ \\
\hline \multirow{4}{*}{$\begin{array}{l}\text { Concomitant } \\
\text { diseases, \% (n) }\end{array}$} & Diabetes mellitus & $31.0 \%(18)$ \\
\hline & Hypertension & $70.7 \%(41)$ \\
\hline & Hyperlipidemia & $56.9 \%(33)$ \\
\hline & Current smoking & $32.8 \%(19)$ \\
\hline \multirow{5}{*}{$\begin{array}{l}\text { Concomitant } \\
\text { medication, } \\
\%(n)\end{array}$} & (Any) Statin & $82.8 \%(48)$ \\
\hline & High-dose statin & $67.2 \%(39)$ \\
\hline & ARB/ACE inhibitor & $72.4 \%(42)$ \\
\hline & $\beta$-Blocker & $82.8 \%(48)$ \\
\hline & Proton pump inhibitor & $79.3 \%(46)$ \\
\hline
\end{tabular}

$P C l$ - percutaneous coronary intervention, $C A D$ - coronary artery disease, STEMI - ST-elevation myocardial infarction, NSTEMI non-ST-elevation myocardial infarction, $A R B$ - angiotensin receptor blocker, ACE - angiotensin-converting enzyme.

DAPT by use of aspirin in combination with different P2Y12-receptor inhibitors. As shown, low HDL-C levels were accompanied by higher ontreatment platelet reactivity, while remnant cholesterol as well as TG exhibited a weaker or no correlation at all. Additionally, diabetes and obesity were associated with markers of platelet function. However, after multivariable adjustment only $\mathrm{HDL}-\mathrm{C}$ levels remained an independent predictor of platelet function.

Recently, Mendelian randomization studies have doubted a causal relationship between genetically low levels of HDL and cardiovascular outcome [22]. Nevertheless, HDL remains a wellaccepted marker of metabolic control, insulin sensitivity and modifiable cardiovascular risk [13, 17, $23,24]$. Notably, in our study, HDL-C was a more accurate predictor of on-treatment platelet function than $\mathrm{HbA}_{1 c}$ levels, history of diabetes, TG levels or known hyperlipidemia (Tables II, III). Insulin resistance plays a key role in the development of dyslipidemia [7] and high on-treatment platelet reactivity was found in patients with diabetes $[25,26]$. However, our study indicates that HDL-C is a much stronger predictor of platelet function when compared to $\mathrm{HbA}_{1 \mathrm{c}}$ in patients with $\mathrm{CAD}$ on 

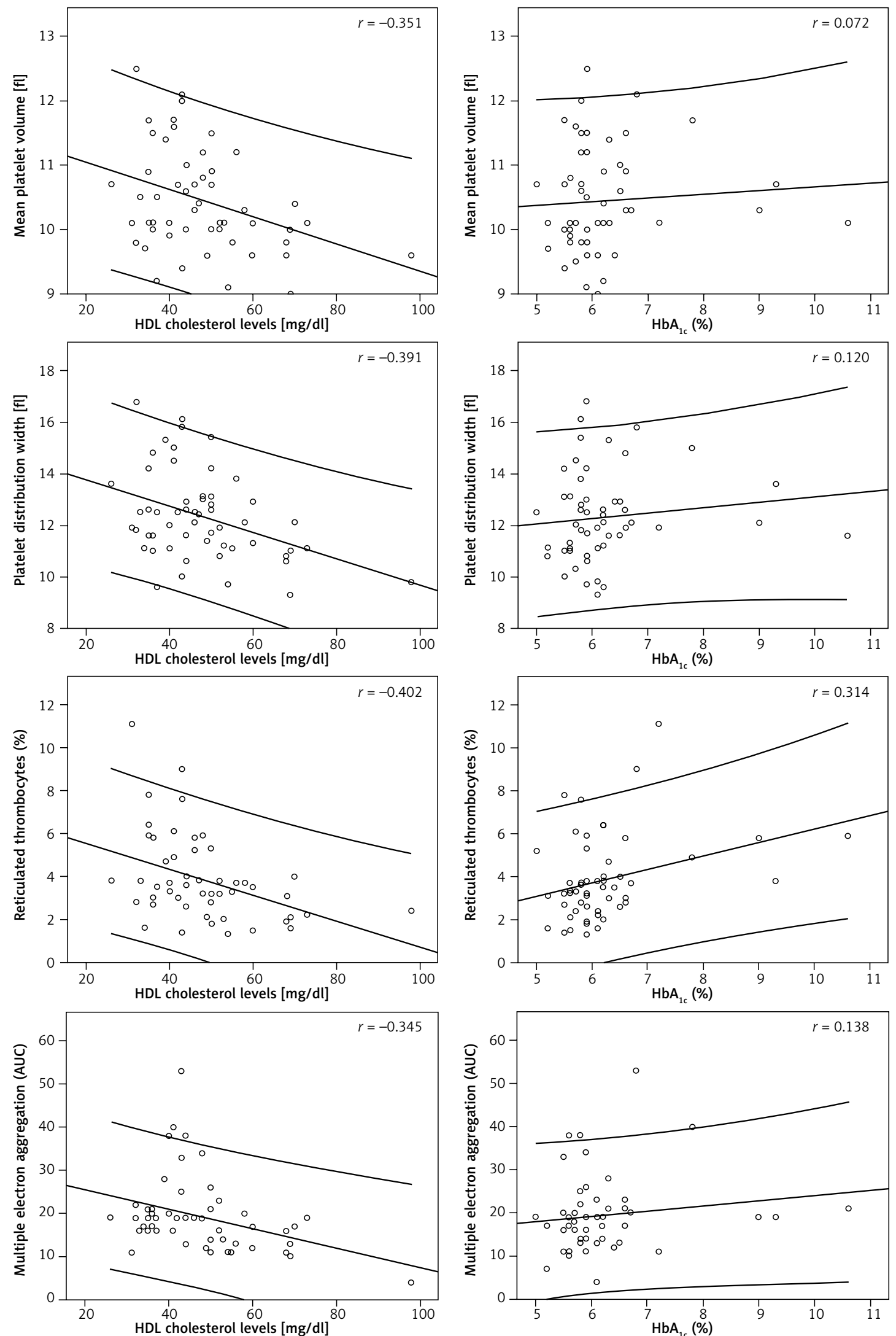

Figure 1. Correlation of $\mathrm{HDL}$ cholesterol, $\mathrm{HbA}_{1 \mathrm{c}}$ and markers of platelet activation. Correlation coefficient $(r)$ for different platelet markers (mean platelet volume, platelet distribution width, fraction of reticulated thrombocytes and multiple electrode aggregometry), $\mathrm{HDL}$ cholesterol and $\mathrm{HbA}_{1 \mathrm{c}}$. A consistent negative correlation is observed for HDL cholesterol and markers of platelet activation (left column), while only a weak to moderate correlation is found between $\mathrm{HbA}_{1 \mathrm{c}}$ and platelet function (right column) 
Table II. Correlation of lipid parameters, $\mathrm{HbA}_{1 \mathrm{c}}$ and markers of platelet activation

\begin{tabular}{|c|c|c|c|c|c|}
\hline Parameter & & $\begin{array}{c}\text { Mean platelet } \\
\text { volume }\end{array}$ & $\begin{array}{l}\text { Platelet distribu- } \\
\text { tion width }\end{array}$ & $\begin{array}{l}\text { Reticulated } \\
\text { thrombocytes }\end{array}$ & $\begin{array}{c}\text { Multiple electrode } \\
\text { aggregometry }\end{array}$ \\
\hline \multirow[t]{2}{*}{ Total cholesterol } & $\begin{array}{l}\text { Pearson } \\
\text { correlation }\end{array}$ & 0.022 & 0.065 & -0.009 & -0.104 \\
\hline & $P$-value & 0.872 & 0.632 & 0.946 & 0.448 \\
\hline \multirow[t]{2}{*}{ HDL cholesterol } & $\begin{array}{l}\text { Pearson } \\
\text { correlation }\end{array}$ & -0.351 & -0.391 & -0.402 & -0.345 \\
\hline & $P$-value & 0.009 & 0.003 & 0.003 & 0.011 \\
\hline \multirow[t]{2}{*}{ LDL cholesterol } & $\begin{array}{l}\text { Pearson } \\
\text { correlation }\end{array}$ & 0.183 & 0.191 & 0.017 & -0.038 \\
\hline & $P$-value & 0.191 & 0.171 & 0.904 & 0.789 \\
\hline \multirow{2}{*}{$\begin{array}{l}\text { HDL cholesterol/ } \\
\text { LDL cholesterol } \\
\text { (ratio) }\end{array}$} & $\begin{array}{l}\text { Pearson } \\
\text { correlation }\end{array}$ & -0.299 & -0.329 & -0.203 & -0.213 \\
\hline & $P$-value & 0.03 & 0.016 & 0.157 & 0.133 \\
\hline \multirow[t]{2}{*}{ Triglycerides } & $\begin{array}{l}\text { Pearson } \\
\text { correlation }\end{array}$ & 0.126 & 0.206 & 0.231 & 0.060 \\
\hline & $P$-value & 0.352 & 0.125 & 0.092 & 0.666 \\
\hline \multirow[t]{2}{*}{$\begin{array}{l}\text { Remnant } \\
\text { cholesterol }\end{array}$} & $\begin{array}{l}\text { Pearson } \\
\text { correlation }\end{array}$ & -0.099 & -0.043 & 0.052 & 0.059 \\
\hline & $P$-value & 0.466 & 0.751 & 0.708 & 0.671 \\
\hline \multirow[t]{2}{*}{$\mathrm{HbA}_{1 \mathrm{c}}$} & $\begin{array}{l}\text { Pearson } \\
\text { correlation }\end{array}$ & 0.072 & 0.120 & 0.314 & 0.138 \\
\hline & $P$-value & 0.600 & 0.384 & 0.024 & 0.325 \\
\hline
\end{tabular}

Table III. Multivariable regression model

\begin{tabular}{|c|c|c|c|c|}
\hline Dependent variable & Multivariable predictors* & $\begin{array}{c}\text { Coefficient } \\
\text { (unstandardized) }\end{array}$ & $95 \% \mathrm{Cl}$ & $P$-value \\
\hline \multirow[t]{3}{*}{ Mean platelet volume } & HDL-C & -0.024 & -0.039 to -0.009 & 0.002 \\
\hline & Sex & -0.543 & -0.061 to -1.025 & 0.028 \\
\hline & Platelet count & -0.004 & -0.001 to -0.008 & 0.015 \\
\hline \multirow{5}{*}{$\begin{array}{l}\text { Platelet distribution } \\
\text { width }\end{array}$} & $\mathrm{HDL}-\mathrm{C}$ & -0.064 & -0.034 to -0.094 & 0.00008 \\
\hline & Sex & -1.068 & -0.084 to -2.052 & 0.034 \\
\hline & Platelet count & -0.011 & -0.004 to -0.018 & 0.002 \\
\hline & Renal function & -0.017 & -0.038 to 0.003 & 0.091 \\
\hline & Index event (ACS/SCAD) & 0.734 & -0.158 to 1.626 & 0.104 \\
\hline \multirow{5}{*}{$\begin{array}{l}\text { Reticulated } \\
\text { thrombocytes }\end{array}$} & $\mathrm{HDL}-\mathrm{C}$ & -0.069 & -0.031 to -0.107 & 0.001 \\
\hline & Platelet count & -0.012 & -0.020 to -0.004 & 0.003 \\
\hline & P2Y12 inhibitor & -0.564 & -1.272 to 0.144 & 0.115 \\
\hline & Diabetes mellitus & 0.989 & -0.077 to 2.056 & 0.068 \\
\hline & Index event (ACS/SCAD) & 1.583 & 0.220 to 2.945 & 0.024 \\
\hline \multirow{4}{*}{$\begin{array}{l}\text { Multiple electrode } \\
\text { aggregometry }\end{array}$} & HDL-C & -0.355 & -0.170 to -0.540 & 0.0003 \\
\hline & Triglycerides & -0.028 & -0.058 to 0.001 & 0.059 \\
\hline & P2Y12 inhibitor & -3.908 & -6.646 to -1.169 & 0.006 \\
\hline & Renal function & -0.085 & -0.195 to 0.025 & 0.126 \\
\hline
\end{tabular}

*Multivariable analysis with step-wise backward elimination of variables using a likelihood ratio test with p-value for entry of 0.05 and $p$-value for removal of 0.15 . The following variables were entered into the model: $H D L$ cholesterol (HDL-C), total cholesterol, triglycerides, sex, age, platelet count, high-dose statin intake, current smoking, index event, P2Y12 inhibitor (clopidogrel, prasugrel, ticagrelor), PPI intake, diabetes mellitus, body mass index, glomerular filtration rate. ACS - acute coronary syndrome, SCAD - stable coronary artery disease. 
contemporary DAPT. Whether the recommended duration of DAPT after coronary stent implantation is reasonable in patients with diabetes is the subject of recently published and ongoing trials; however, previous studies failed to show a clear benefit of prolonged DAPT in diabetic patients $[4,5,27]$. In the past, clinical studies evaluating the optimal duration of DAPT focused neither on dyslipidemia as a clinical risk factor nor on HDL-C as a laboratory marker. As these studies did not report HDL-C levels, it remains unclear whether diabetic patients with dyslipidemia (indicated by HDL-C levels), rather than a history of diabetes alone, comprise a population who would benefit from extended DAPT. Moreover, dysfunctional $\mathrm{HDL}$ was shown to be involved in the process of atherosclerosis, indicating that HDL functionality should be determined in addition to HDL quantity [28]. Future clinical studies investigating the optimal duration of DAPT in patients with CAD should therefore focus on metabolic biomarkers in addition to clinical and angiographic parameters.

Interestingly, in our study, low HDL-C levels were not only linked to increased ADP-mediated platelet activation, but also were associated with markers of platelet turnover, younger, immature and more reactive platelets (reticulated platelets, PDW), and MPV, a general indicator of platelet activation and enzymatic activity [29]. Reticulated platelets are newly formed platelets which are larger in size and have higher granule content [30]. Larger platelets are metabolically and enzymatically more active, and have greater prothrombotic potential. They are more often reticulated, which is an independent predictor of poor response to dual antiplatelet therapy $[18,31]$. On the other hand, high-on-platelet reactivity is a well-established predictor of cardiovascular events and mortality in patients with CAD [32].

The MPV was extensively studied as a diagnostic and prognostic tool in ACS [18], and furthermore has been proposed as a marker to guide utilization of abciximab in patients with acute MI [33]. Analogously, high MPV correlated with increased metabolic risks in our study and was recently shown to decline after glycemic control in diabetes [34]. HDL-C therefore possibly indicates the need for intensified antithrombotic treatment in the setting of stable CAD. Moreover, HDL-C levels were associated with platelet function independently of a history of diabetes or glycemic control, as indicated by $\mathrm{HbA}_{1 \mathrm{c}}$ levels. In light of these data, we conclude that HDL-C provides additional information on a patient's thrombotic risk, on top of established clinical parameters. Therefore, HDL-C possibly could serve as a biomarker to identify patients with potential benefits of DAPT prolonged over the currently recommended duration.
There are several limitations to consider: First of all, the study population consists of only 58 patients and was further divided according to the choice of P2Y12 inhibitor. We also did not include a control group of healthy subjects. However, the study cohort is very well balanced in terms of baseline characteristics and patients received optimal contemporary concomitant pharmacological treatment and modern coronary drug-eluting stents. It therefore resembles a relevant, well-treated cohort of CAD patients. Remnant cholesterol was not measured directly, but calculated via a previously verified formula. Similarly, the Friedewald equation was used to assess LDL-C levels, which resembles daily clinical life and makes our results replicable. However, LDL-C levels calculated from non-fasting samples might be of limited value, as some data suggest that the Friedewald equation requires a fasting sample [35]. As our study intended to investigate the relationship of routine lipid parameters and platelet activity from a clinical point of view, we did not focus on investigating connections at a pathophysiological level. Finally, our study is based on well-accepted and common markers used in clinical routine, and hence the present results are easily applicable in daily clinical practice.

In conclusion, in contrast to other routine lipid parameters, HDL-C levels inversely correlate with routine and scientific markers of platelet activation in patients with CAD on DAPT. Accordingly, patients with dyslipidemia might benefit from prolonged antiplatelet therapy, which should be addressed in future clinical trials.

\section{Acknowledgments}

The research was supported by the Ludwig Boltzmann Cluster for Cardiovascular Research, Vienna, and the Association for the Promotion of Research in Arteriosclerosis, Thrombosis and Vascular Biology (ATVB), Vienna.

\section{Conflict of interest}

Bernhard Jäger and Kurt Huber received an unrestricted research grant from Astra Zeneca. All other co-authors report no conflicts of interest.

\footnotetext{
References

1. Roffi M, Patrono C, Collet JP, et al. 2015 ESC Guidelines for the management of acute coronary syndromes in patients presenting without persistent ST-segment elevation: Task Force for the Management of Acute Coronary Syndromes in Patients Presenting without Persistent ST-Segment Elevation of the European Society of Cardiology (ESC). Eur Heart J 2016; 37: 267-315.

2. Windecker S, Kolh P, Alfonso F, et al. 2014 ESC/EACTS Guidelines on myocardial revascularization: The Task Force on Myocardial Revascularization of the European
} 
Society of Cardiology (ESC) and the European Association for Cardio-Thoracic Surgery (EACTS) Developed with the special contribution of the European Association of Percutaneous Cardiovascular Interventions (EAPCI). Eur Heart J 2014; 35: 2541-619.

3. Task Force on the management of STseamiotESoC, Steg PG, James SK, Atar D, Badano LP, Blomstrom-Lundqvist $C$, et al. ESC Guidelines for the management of acute myocardial infarction in patients presenting with ST-segment elevation. Eur Heart J 2012; 33: 2569-619.

4. Mauri L, Kereiakes DJ, Yeh RW, et al. Twelve or 30 months of dual antiplatelet therapy after drug-eluting stents. N Engl J Med 2014; 371: 2155-66.

5. Bonaca MP, Bhatt DL, Cohen M, et al. Long-term use of ticagrelor in patients with prior myocardial infarction. N Engl J Med 2015; 372: 1791-800.

6. Yeh RW, Secemsky EA, Kereiakes DJ, et al. Development and validation of a prediction rule for benefit and harm of dual antiplatelet therapy beyond 1 year after percutaneous coronary intervention. JAMA 2016; 315: 1735-49.

7. Wu L, Parhofer KG. Diabetic dyslipidemia. Metabolism 2014; 63: 1469-79.

8. Assmann G, Schulte H, von Eckardstein A, Huang Y. High-density lipoprotein cholesterol as a predictor of coronary heart disease risk. The PROCAM experience and pathophysiological implications for reverse cholesterol transport. Atherosclerosis 1996; 124 Suppl: S11-20.

9. Castelli WP, Garrison RJ, Wilson PW, Abbott RD, Kalousdian S, Kannel WB. Incidence of coronary heart disease and lipoprotein cholesterol levels. The Framingham Study. JAMA 1986; 256: 2835-8.

10. Annema W, von Eckardstein A. High-density lipoproteins. Multifunctional but vulnerable protections from atherosclerosis. Circ J 2013; 77: 2432-48.

11. Varbo A, Benn M, Tybjaerg-Hansen A, Jorgensen AB, Frikke-Schmidt R, Nordestgaard BG. Remnant cholesterol as a causal risk factor for ischemic heart disease. J Am Coll Cardiol 2013; 61: 427-36.

12. Libby P. Triglycerides on the rise: should we swap seats on the seesaw? Eur Heart J 2015; 36: 774-6.

13. Nordestgaard BG, Varbo A. Triglycerides and cardiovascular disease. Lancet 2014; 384: 626-35.

14. Korporaal SJ, Akkerman JW. Platelet activation by low density lipoprotein and high density lipoprotein. Pathophysiol Haemost Thromb 2006; 35: 270-80.

15. Naqvi TZ, Shah PK, Ivey PA, et al. Evidence that high-density lipoprotein cholesterol is an independent predictor of acute platelet-dependent thrombus formation. Am J Cardiol 1999; 84: 1011-7.

16. Calkin AC, Drew BG, Ono A, et al. Reconstituted highdensity lipoprotein attenuates platelet function in individuals with type 2 diabetes mellitus by promoting cholesterol efflux. Circulation 2009; 120: 2095-104.

17. Lerch PG, Spycher MO, Doran JE. Reconstituted high density lipoprotein ( $\mathrm{rHDL}$ ) modulates platelet activity in vitro and ex vivo. Thromb Haemost 1998; 80: 316-20.

18. Chu SG, Becker RC, Berger PB, et al. Mean platelet volume as a predictor of cardiovascular risk: a systematic review and meta-analysis. J Thromb Haemost 2010; 8: 148-56.

19. Toth O, Calatzis A, Penz S, Losonczy H, Siess W. Multiple electrode aggregometry: a new device to measure platelet aggregation in whole blood. Thromb Haemost 2006; 96: 781-8.

20. Varbo A, Benn M, Nordestgaard BG. Remnant cholesterol as a cause of ischemic heart disease: evidence, definition, measurement, atherogenicity, high risk patients, and present and future treatment. Pharmacol Ther 2014; 141: 358-67.

21. Sharma M, Ansari MT, Abou-Setta AM, et al. Systematic review: comparative effectiveness and harms of combination therapy and monotherapy for dyslipidemia. Ann Intern Med 2009; 151: 622-30.

22. Haase CL, Tybjaerg-Hansen A, Nordestgaard BG, FrikkeSchmidt R. HDL cholesterol and risk of type 2 diabetes: a mendelian randomization study. Diabetes 2015; 64: 3328-33.

23. Ghomari-Boukhatem H, Bouchouicha A, Mekki K, Chenni K, Belhadj M, Bouchenak M. Blood pressure, dyslipidemia and inflammatory factors are related to body mass index in scholar adolescents. Arch Med Sci 2017; 13: 46-52.

24. Stulc T, Lanska V, Snejdrlova M, Vrablik M, Prusikova M, Ceska R. A comprehensive guidelines-based approach reduces cardiovascular risk in everyday practice: the VARO study. Arch Med Sci 2017; 13: 705-10.

25. Angiolillo DJ, Fernandez-Ortiz A, Bernardo E, et al. Platelet function profiles in patients with type 2 diabetes and coronary artery disease on combined aspirin and clopidogrel treatment. Diabetes 2005; 54: 2430-5.

26. Freynhofer MK, Bruno V, Brozovic I, et al. Variability of on-treatment platelet reactivity in patients on clopidogrel. Platelets 2014; 25: 328-36.

27. Kwok CS, Bulluck H, Ryding AD, Loke YK. Benefits and harms of extending the duration of dual antiplatelet therapy after percutaneous coronary intervention with drug-eluting stents: a meta-analysis. Sci World J 2014; 2014: 794078.

28. Otocka-Kmiecik A, Mikhailidis DP, Nicholls SJ, Davidson M, Rysz J, Banach M. Dysfunctional HDL: a novel important diagnostic and therapeutic target in cardiovascular disease? Prog Lipid Res 2012; 51: 314-24.

29. Freynhofer MK, Gruber SC, Grove EL, Weiss TW, Wojta J, Huber K. Antiplatelet drugs in patients with enhanced platelet turnover: biomarkers versus platelet function testing. Thromb Haemost 2015; 114: 459-68.

30. Lakkis N, Dokainish H, Abuzahra M, et al. Reticulated platelets in acute coronary syndrome: a marker of platelet activity. J Am Coll Cardiol 2004; 44: 2091-3.

31. Guthikonda S, Alviar CL, Vaduganathan M, et al. Role of reticulated platelets and platelet size heterogeneity on platelet activity after dual antiplatelet therapy with aspirin and clopidogrel in patients with stable coronary artery disease. J Am Coll Cardiol 2008; 52: 743-9.

32. Aradi D, Kirtane A, Bonello L, et al. Bleeding and stent thrombosis on P2Y12-inhibitors: collaborative analysis on the role of platelet reactivity for risk stratification after percutaneous coronary intervention. Eur Heart J 2015; 36: 1762-71.

33. Estevez-Loureiro R, Salgado-Fernandez J, Marzoa-Rivas $R$, et al. Mean platelet volume predicts patency of the infarct-related artery before mechanical reperfusion and short-term mortality in patients with ST-segment elevation myocardial infarction undergoing primary percutaneous coronary intervention. Thromb Res 2009; 124: 536-40.

34. Sertbas Y, Sertbas M, Okuroglu N, Ozturk MA, Abacar KY, Ozdemir A. Mean platelet volume changes before and after glycated hemoglobin (HbA1c) improvement in a large study population. Arch Med Sci 2017; 13: 711-5.

35. Mora S, Rifai N, Buring JE, Ridker PM. Comparison of LDL cholesterol concentrations by Friedewald calculation and direct measurement in relation to cardiovascular events in 27,331 women. Clin Chem 2009; 55: 888-94. 